\title{
The effects of three training methods endurance, resistance and concurrent on adiponectin resting levels in overweighed untrained men
}

\author{
Asad $\mathrm{M}^{1}$, Ravasi AA ${ }^{2}$, Faramarzi $\mathrm{M}^{3}$, Pournemati $\mathrm{P}^{4}$ \\ Payam Nour University, Sport Physiology Department, Tehran, Iran. Asad_mohammadreza@yahoo.com
}

\begin{abstract}
The purpose of present study was to investigate the impacts of endurance, resistance and concurrent training on adiponectin resting levels of sedentary men. Forty-four sedentary students were randomly assigned to one of four groups: endurance training $(E T ; 22 \pm 0.89 \mathrm{yr}, \mathrm{n}=12)$, resistance training $(\mathrm{RT}, 21 \pm 1.57$ $\mathrm{yr}, \mathrm{n}=9)$, concurrent training $(C T, 21.38 \pm 2.6 \mathrm{yr}, \mathrm{n}=14)$ and control group $(C G, \mathrm{n}=10)$. After primary measurements, blood samples were drawn with subjects in fasting and resting state for determination of the basic level of adiponectin. The subjects participated in E, R and C training for 8 weeks. The ET group ran $3 \mathrm{~d} / \mathrm{w}$ at $65-85$ $\%$ of maximum heart rate. The exercise training session for the RT group consisted of 3 sets of 10-15 repetitions of weight training exercise that increase progressively, and repeated 3 sessions per week. The CT group trained exactly the sum of ET and RT groups. Correlated samples t-test and ANOVA were used. The results of the present study showed that after the eight-week training, the adiponectin levels of subjects increased in 3 groups of training but this increase was not significant. The level of adiponectin in CT group increased more than in ET and RT groups. Also, there were no significant differences in content of adiponectin among groups. In general, slight increases in adiponectin levels in training groups especially in CT group may indicate the most potential of CT group in increasing the levels of adiponectin in sedentary men. However more researches are needed to identify the effects of concurrent training
\end{abstract}

(Tab. 4, Ref. 27). Full Text in PDF www.elis.sk.

Key words: adiponectin, endurance training, resistance training, concurrent training.

Adipose tissue is a source of many factors derived from adipocyte. Adipocytokines point to active biologic molecules that are derived from fat cells. Some of these adipocytokines mediate the systemic effect of obesity. Recently, adiponectins have been recognized as adipocytokines with an important metabolic effect $(11,12)$.

Adiponectin is a protein with 244 amino acids and is released in a large amount from human adipose tissue. The contrast of this cytokine is high in blood, and in fact it contains 0.01 percent of the total of serum proteins (17). Although adiponectin is released only from white adipose tissue, unlike most adipokines its gene expression in white adipose tissue and serum contrasts the decrease in obesity and overweight. Beside its antiinflammatory effects, the important effect of adiponectin that has been taken into consideration is its relationship to risk factors of metabolic syndrome.

${ }^{1}$ Payam Nour University, Sport Physiology Department, Tehran, Iran, ${ }^{2}$ University of Tehran, Sport Physiology Department, Tehran, Iran, ${ }^{3}$ University of Shahrekord, Sport Physiology Department, University of Tehran, and ${ }^{4}$ Physical Educational Faculty, Sport Physiology Department, Membership of Sport Medicine Research Center, Tehran University of Medical Science, Tehran, Iran

Address for correspondence: P. Pournemati, No.15, Yazdan Niaz street, North Bahar Ave, Taleghani Ave, Tehran, Iran

Phone: +989123490124
The results of some researchers have demonstrated that a decrease in adiponectin relates to insulin resistance, hyperinsulinism and hyperglycemia (21).

Furthermore researches on different races have reported that adiponectin levels increase after weight loss and improvement of insulin resistance $(5,20)$.

When compared to other adipocytokines, plasma adiponectin decrease after obesity and insulin resistance. It is described that maybe other adipocytokines have their effects on insulin resistance by affecting adiponectin gene expression and its release (13). Adiponectin may affect fatty acid oxidation in skeletal muscle and consequently decrease TG in skeletal muscle fibers and increase lipoproteins catabolism. Nevertheless adiponectin may decrease the flow of fatty acids to the liver and production of liver glucose (13).

Also it may be that adiponectin has antiatherogenic and antiinflammatory effects while it acts as a mediator between obesity and atherosclerosis (18).

One of assumed mechanisms of how exercise can decrease inflammatory processes is via weight loss. Weight loss can decrease cytokines production from adipose tissue (7). Of course one of effective factors in altering the body composition especially that of adipose tissue is the balance between energy intake and consumption. To change the body composition, it is the endurance training that is usually used due to its ability to increase energy expenditure 
and use fats. Although the results of previous studies investigating the effects of endurance training on BMR are different, some of them show an increase in $\operatorname{RMR}(1,3,24)$ but other show no difference in BMR (19) or a decrease in RMR (3).

It is reported that different factors affect the amount of metabolism. The strongest relationship is between FFM and BMR. It is thought that increasing the lean body mass increases BMR and then total energy expenditure increases (15).

Generally, fat mass and total body mass decrease with endurance training, however this decrease interferes very little with the increase in lean body mass (23). Many researches focus on increasing lean body mass with resistance training. Although some researches have been done on the effect of training on adiponectin concentrations and its relation with increasing insulin sensitivity, in most of them it is reported that plasma adiponectin concentrations have not changed with training in healthy subjects. For example Hulver et al (2002) reported insulin activity improved after sixmonth endurance training but plasma adiponectin concentrations did not change in healthy subjects (6). Plasma adiponectin did not increase in healthy young men after a long walking program (10). Also in elite rowers, plasma adiponectin did not increase significantly in training season (4), but after a six-month endurance training plasma adiponectin concentrations decreased by $18 \%$ compared with pre-training in healthy men (25). Zeng et al (2007) demonstrated that exercise-induced changing in total plasma adiponectin depends on intensity and duration of training (26). Few studies have been done on resistance training. Some of them demonstrated that resistance training significantly decreased the insulin resistance index in obese men but it did not affect serum adiponectin significantly.

Hara et al (2005) used aerobic and resistance training with each other and reported no difference in adiponectin (4). Concurrent training is a recently new method in training programs. Researchers demonstrated positive effects on body composition by concurrent training such as increasing FFM, and decreasing FM and body fat percentage. In another way Jurimae et al (2005) hypothesized that if energy consumption is intensified during exercise and has higher metabolic pressure, the probability of increasing the exerciseinduced adiponectin is greater (8). So, by paying attention to few researches about the effect of concurrent training on adiponectin and its effect on energy expenditure and body composition especially fat mass and fat percentage, it is required to study the effect of such a training program and compare these two traditional methods (endurance and resistance) on adiponectin changes. As a result the aim of present study was to demonstrate the effect of three training methods, namely endurance, resistance and concurrent on adiponectin in sedentary healthy men.

\section{Methods}

\section{Subjects}

Forty-four sedentary healthy college students took part in this study (Tab. 1). They did not have former regular exercise training and while being awarded with the goal of the study they signed a letter of satisfaction. Then they were divided to four groups: resistance training ( 9 persons), endurance training (12 persons), concurrent training (13 persons) and control group (10 persons). At first height, weight, fat percentage, $\mathrm{BMI}$ and $\mathrm{VO}_{2} \max$ of subjects were evaluated (Tab. 1).

Training protocol: After primary evaluations and measuring the basic levels of indexes, the subjects took part in resistance, endurance or concurrent trainings three days per week for 8 weeks.

Enduring training program: Endurance training program was composed of a running program with duration and intensity increased gradually at the end of each level. In first and second weeks, the subjects worked out at $65 \%$ of MHR for 25 minutes. From third until the sixth week they worked out at $65-75 \%$ of MHR for 35 minutes and from seventh till eighth week at 75-85 $\%$ of MHR for 40 minutes. For controlling their heart rate, polar belts were used.

Resistance training group: The subjects of this group took part in a resistance training program with machines and free loads. The training program contained upper body training and lower body training such as bench press, sitting \& standing up with halter, leg extension, leg flexion, leg press and rowing.

In the first two weeks, subjects did three sets with 10-15 repetition and in the next six weeks their training was set for them in a way that they could not do 10-12 repetition in first set, 8-10 repetition in second set and 4-8 repetitions in third set.

Concurrent training group: These subjects took part in a training program that exactly summed the endurance and resistance training. For this group endurance and resistance training programs were done exactly in the same days with two other groups but the resistance training was always done first.

\section{Adiponectin measuring}

For measuring adiponectin, blood samples were taken after 12-h fasting, and after separating the serum it was stored at -80 ${ }^{\circ} \mathrm{C}$. Adiponectin measuring was done with ELISA and its special kit (Biovendore).

\section{Statistic methods}

Descriptive statistics was used to assign mean and standard deviations. Kolmagrov-Smirnof was used for defining normal distribution. Change in each group was demonstrated with dependent T while for comparing changes between groups ANOVA was used.

\section{Results}

Table 1 shows mean and standard deviations of age, height, weight, body mass and $\mathrm{VO}_{2}$ max.

Table 2 shows mean and standard deviations for adiponectin before and after training. The results of adiponectin levels after training indicate that in concurrent group they are highest among all groups.

Table 3 shows adiponectin concentrations before and after training in each of the training groups and in control group.

The results of Table 2 show that there is no significant difference between adiponectin concentrations before and after training in endurance, resistance and concurrent training groups. 
664-668

Tab. 1. Mean and standard deviations of age, height, weight, body mass and $\mathrm{VO}_{2}$ max.

\begin{tabular}{|c|c|c|c|c|c|c|c|c|}
\hline \multirow[t]{2}{*}{ Groups } & \multicolumn{2}{|c|}{ Endurance $(n=12)$} & \multicolumn{2}{|c|}{ Resistance $(n=9)$} & \multicolumn{2}{|c|}{ Concurrent $(n=13)$} & \multicolumn{2}{|c|}{ Control $(n=10)$} \\
\hline & Pre & Post & Pre & Post & Pre & Post & Pre & Post \\
\hline BMI & $29.86 \pm 3.94$ & $28.70 \pm 3.59$ & $31.48 \pm 4.95$ & $30.44 \pm 4.80$ & $28.64 \pm 3.76$ & $27.38 \pm 3.67$ & $29.26 \pm 4.27$ & $29.29 \pm 4.40$ \\
\hline VO2max & $27.72 \pm 5.99$ & $33.75 \pm 5.38$ & $26.10 \pm 4.47$ & $32.49 \pm 4.04$ & $27.83 \pm 3.76$ & $35.64 \pm 6.44$ & $31.19 \pm 6.39$ & $31.02 \pm 5.00$ \\
\hline weight & $90.55 \pm 10.80$ & $87.50 \pm 11.07$ & $92.22 \pm 15.85$ & $89.17 \pm 15.29$ & $86.61 \pm 15.05$ & $83.46 \pm 14.02$ & $90.00 \pm 14.05$ & $90.33 \pm 14.60$ \\
\hline height & $174.64 \pm 4.72$ & -- & $171.11 \pm 5.51$ & -- & $173.65 \pm 7.07$ & -- & $175.61 \pm 5.09$ & -- \\
\hline age & $22.0 \pm 0.89$ & -- & $21.0 \pm 1.57$ & -- & $21.38 \pm 2.06$ & -- & $21.44 \pm 1.13$ & -- \\
\hline
\end{tabular}

Tab. 2. Adiponectin mean standard deviations before and after training in each group.

\begin{tabular}{llccc}
\hline & Group & Amount & Mean & SD \\
\hline Adiponectin & Endurance & 12 & 16.67 & 2.35 \\
before training & Resistance & 9 & 16.67 & 2.35 \\
& concurrent & 13 & 17 & 5.37 \\
& control & 10 & 20.30 & 8.35 \\
Adiponectin & Endurance & 12 & 17.56 & 1.51 \\
after training & Resistance & 9 & 17.56 & 1.51 \\
& concurrent & 13 & 20.38 & 7.61 \\
& control & 10 & 18.80 & 2.69 \\
\hline
\end{tabular}

The result of ANOVA is shown in Table 4 and indicates that adiponectin had no significant difference between the groups.

The results of present study demonstrate that although there was a little increase in all three groups but there is no significant difference in adiponectin concentration before and after training in three groups. And also there is no significant difference in adiponectin concentrations between the groups.

\section{Conclusion}

Although the results of present study show increasing values after training in all groups they were not significantly meaningful within groups as well as between groups. Naturally the increase in adiponectin was the greatest in the concurrent group. The resulting changes achieved in this study on adiponectin are similarly insignificant as those achieved by Yatagai (2003), Kobayashi (2006), Rouzen Bavem (2007) and Jurimae (2006).

Yatagai et al (2003) studied adiponectin concentrations after six-week rowing on ergometer (five sessions per week at the intensity of lactate threshold) in healthy men with normal weight. The results show that BMI and fat mass did not change after six weeks of training. The amount of adiponectin hormone decreased 16 hours after training but it came back to normal concentrations after a week. Researchers concluded that in healthy persons, increasing exercise-induced insulin sensitivity has no relation to increasing of plasma adiponectin and it seems that decreasing the fat mass and BMI of subjects after training have a role in increasing the adiponectin concentrations (25).
Tab. 4. The results of variance for comparing changes between groups.

\begin{tabular}{lccc}
\hline & df & F & P \\
\hline Between group & 3 & 0.768 & 0.519 \\
Within group & 40 & & \\
\hline Total & 43 & & \\
\hline
\end{tabular}

Kobayashi et al (2006) studied the effect of a walking program (50 days with a mean of $8211 \pm 2084$ steps/day) on metabolic parameters such as adiponectin in healthy men. Their results show a significant decrease in BMI, TG, $\mathrm{TNF}_{\alpha}$, after their training program, nevertheless plasma adiponectin, fat weight and fat percentage did not change. By paying attention to increasing the adiponectin following a significant decrease in body weight, the researchers reported that the probable reason for invariability of adiponectin in their study was the intensity of training program that did not decrease the weight and body fat percentage (10). In another study that was done by Rouzen Bavem (2007), 73 students of eighth grade took part in aerobic training program (rhythmic performance, 3 sessions/week) for 3-4 months. At the end of the program, the body fat percentage and insulin sensitivity decreased but adiponectin concentrations did not change (16).

Jurimae et al (2006) studied the plasma adiponectin response to training in elite rowers in training season. They took part in specific training for 6 months. Plasma adiponectin was measured before and after the test. The results show that after six months plasma adiponectin changed in neither of groups in resting state (8).

By paying attention to results of previous studies it seems that in healthy persons with normal weight, plasma adiponectin concentration is not affected by long-term training program. In another way Polak et al (2006) studied the effect of aerobic training program on plasma concentration of adiponectin and $\mathrm{TNF}_{\alpha}$, and both adiponectins mRNA. The subjects of that study were 25 sedentary premenopause obese women $\left(\mathrm{BMI}=32.2 \pm 2.2 \mathrm{~kg} / \mathrm{m}^{2}\right)$. They were subdued to aerobic training for 45 minutes each day, 5 days/week for 12 weeks with $50 \% \mathrm{VO}_{2}$ max.

The results show that their weight and fat mass decreased by $5.9 \%$ and $6.4 \%$, respectively. Also there were no changes in plasma adiponectin and plasma $\mathrm{TNF}_{\alpha}$ and the expression of both adiponectins in adipose tissue. The researchers described two hy-

Tab. 3. Adiponectin concentrations before and after training.

\begin{tabular}{|c|c|c|c|c|c|c|c|}
\hline & \multicolumn{2}{|c|}{ Mean \pm SD } & \multirow{2}{*}{ Amount } & \multirow{2}{*}{$\mathrm{df}$} & \multirow{2}{*}{$\mathrm{t}$} & \multirow{2}{*}{$\mathrm{p}$} & \multirow{2}{*}{ Result } \\
\hline & pre & post & & & & & \\
\hline Endurance & $16.67 \pm 2.35$ & $17.56 \pm 1.51$ & 12 & 11 & -1.502 & 0.164 & Ns \\
\hline Resistance & $16.67 \pm 2.35$ & $17.56 \pm 1.51$ & 9 & 11 & -0.951 & 0.369 & Ns \\
\hline Concurrent & $17.00 \pm 5.37$ & $20.38 \pm 7.61$ & 13 & 12 & -1.087 & 0.298 & Ns \\
\hline Control & $20.30 \pm 8.35$ & $18.80 \pm 2.69$ & 10 & 9 & 0.513 & 0.621 & Ns \\
\hline
\end{tabular}


potheses for this invariance. Firstly, the aerobic training in this research did not lead to any significant weight loss and thus did not affect adiponectin. Secondly, it seems that exercise-induced increasing of catecholamines can inhibit adiponectin gene expression and its amount in plasma (18). So by paying attention to invariance of subject's weight in this research, these mechanisms can interfere with adiponectin changes (18).

Kelly et al (2007) studied the effect of training on plasma adiponectin and $\mathrm{TNF}_{\alpha}$ in children with overweight (BMI $\left.>30\right)$. The subjects were 20 children at age of 10-12 divided in two groups, namely training group and control group. The training program contained four ergometer sessions/week for eight weeks. The intensity in the first week was at $50-60 \%$ of $\mathrm{VO}_{2} \max$ and in the eighth week it was at $70-80 \%$ of $\mathrm{VO}_{2}$ max. The duration of each session in the first week was 30 minutes and gradually increased up to 50 minutes in the eighth week. The results show that weight, BMI, body fat percentage and upper body fat percentage did not significantly change. Also $\mathrm{TNF}_{\alpha}$ and adiponectin did not change after training. The researchers concluded that exercise that neither decreased weight nor improved body composition, could not affect adiponectin, and if so, only with little effect (9).

As mentioned, in three previous studies the researchers concluded that the reason of invariability of adiponectin concentration after training in obese persons or in persons with overweight lied in the fact that weight or body composition did not decrease or improve respectively. However, Allery et al (2005) reported that after an aerobic training program, the body composition and especially abdomen visceral fat improved but plasma adiponectin did not change. These researchers studied the effect of a twelveweek aerobic training on glucose metabolism, body composition and plasma adiponectin in 16 obese old men and women (at mean age of 61 years, $\mathrm{BMI}=33.2 \pm 1.4 \mathrm{~kg} / \mathrm{m}^{2}$ ) who took part in an aerobic exercise (running) on a treadmill or ergometer five days/week for 60 minutes at $85 \%$ of MHR). The results show that exercise improved insulin resistance and decreased the body weight, fat mass, visceral and subcutaneous fat and abdominal visceral fat, nevertheless plasma adiponectin and $\mathrm{TNF}_{\alpha}$ did not change. Also there was not any correlation between adiponectin and abdominal visceral fat changes (14).

Hara et al (2005) studied the effect of aerobic training and concurrent training (aerobic and resistance) on plasma adiponectin hormone. The subjects of their study were young obese men (BMI $=31.1 \pm 4.2 \mathrm{~kg} / \mathrm{m}^{2}$ ) who were divided in three groups (aerobic, concurrent and control). Aerobic training program was composed of eight weeks of running on a treadmill or ergometer in three sessions/week while each session lasted more than 30 minutes at 54.8 $\%$ of $\mathrm{VO}_{2}$ max. In the concurrent group the aerobic training was done plus resistance training for five months. Body composition and adiponectin have been measured before and after training. In aerobic training group, the body weight and BMI did not change whereas fat mass decreased significantly. Also adiponectin increased by $8.1 \%$ in this group but it was not significant. In concurrent group, the body weight, BMI, fat percentage and fat weight decreased significantly and adiponectin increased by $6.5 \%$ but it was not significant statistically. It is reported that the amount of changes in adiponectin have significant negative correlation with the decrease in body weight, BMI and fat mass. The results of regression analysis also distinguished the body fat percentage to be an anticipator of plasma adiponectin. The researchers reported that it seems that exercise-induced changes in adiponectin took place via changes in body composition, so for increasing plasma adiponectin in obese men, a training that improves body composition is required (4). There are different studies about the effect of exercise on plasma adiponectin in subjects with insulin resistance and diabetes II. In some of them it is reported that plasma adiponectin or its mRNA in adipose tissue increased after exercise (2) but in others there were no significant changes. In people that had resistance training records or they were runners and also did resistance training, adiponectin levels increased by $30 \%$ and 37 $\%$, respectively after a session of weight training (22). Generally it seems there are different reasons and mechanisms in invariability of adiponectin in present study and that one of them may lie in the unchanged body weight of subjects. Also the duration and intensity of training are important. A small increase in adipnectin in three groups especially in the concurrent group shows that this program has a greatest effect on changing adiponectin levels in untrained people. It seems that more studies with longer duration are required for distinguishing the exact effects.

\section{References}

1. Ballor DL, PoehIman ET, Ballor DL. Resting metabolic rate and coronary-heart-disease risk factors in aerobically and resistance trained women. Am J Clin Nutr 1992; 56: 968-974.

2. Blüher M, Bullen JW, Lee JH, Kralisch S, Fasshauer M, Klöting N, Niebauer J, Schön MR, Williams CJ, Mantzoros CS. Circulating adiponectin and expression of adiponectin receptors in human skeletal muscle: associations with metabolic parameters and insulin resistance and regulation by physical training, J Clin Endocrinol Metab 2006; 91: 2310-2316.

3. Broeder CE, Burrhus KA, Svanevik LS, Wilmore JH. The effects of either high-intensity resistance or endurance training on resting metabolic rate. Am J Clin Nutr 1992; 55: 802-810.

4. Hara T, Fujiwara H, Nakao H, Mimura T, Yoshikawa T, Fujimoto S. Body composition is related to increase in plasma adiponectin levels rather than training in young obese men. Eur J Appl Physiol 2005; 94: 520-526.

5. Hu E, Liang P, Spiegelman BM. AdipoQ is a novel adipose-specific gene dysregulated in obesity. J Biol Chem1996; 271: 10 697-10 703.

6. Hulver MW, Zheng D, Tanner CJ, Houmard JA, Kraus WE, Slentz CA, Sinha MK, Pories WJ, MacDonald KG, Dohm GL. Adiponectin is not altered with exercise training despite enhanced insulin action. Am J Physiol Endocrinol Metab 2002; 283: E861-E865.

7. Ischander M, Zaldivar F Jr, Eliakim A et al. Physical activity, growth, and inflammatory mediators in BMI matched female adolescents. Med Sci Sports Exerc 2007; 39: 1131-1138

8. Jurimae J, Purge P, Jurimae T. Adiponectin and stress hormone responses to maximal sculling after volume-extended training season in elite rowers. Metabolism 2006; 55: 13-19.

9. Kelly AS, Steinberger J, Olson TP, Dengel DR. In the absence of weight loss, exercise training does not improve adipokines or oxidative stress in overweight children. Metabolism 2007; 56: 1005-1009. 
$664-668$

10. Kobayashi J, Murase Y, Asano A. Effect of walking with a pedometer on serum lipid and adiponectin levels in Japanese middle-aged men, J Atheroscler Thromb 2006;13:197-201.

11. Maeda K, Okubo K, Shimomura I, Funahashi T, Matsuzawa Y, Matsubara K. DNA cloning and expression of a novel adipose Specific

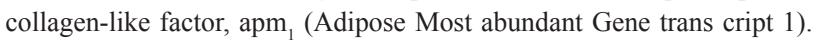
Bioclem Biophys Res Commun 1996; 221: 286-289.

12. Mantzoros CS. The role of leptin in human obesity and disease: a review of current evidence. Annals of Internal Medicine 1999; 130: 651-657.

13. Matsuzawa Y, Funahashi T et al. Adiponectin and the metabolic syndrome. Arterioscler Thromb Vasc Biol 2004; 29-33.

14. O'Leary VB, Jorett AE, Marchetti CM, Gonzalez F, Phillips SA, Ciaraldi TP, Kirwan JP. Enhanced adiponectin multimer ratio and skeletal muscle adiponectin receptor expression following exercise training and diet in older insulin resistant adults, Am J Physiol Endocrinol Metab 2007; 293: E421-E427.

15. Poehlman ET. A review: exercise and its influence on resting energy metabolism in man. Med. Sci. Sports Exerc. 1989; 21: 515-525.

16. Rosenbaum M, Nonas C, Weil R, Horlick M, Fennoy I, Vargas I, Kringas P; El Camino Diabetes Prevention Group, School-based intervention acutely improves insulin sensitivity and decreases inflammatory markers and body fatness in junior high school students. J Clin Endocrinol Metab 2007; 92: 504-508.

17. Scherer PE, Williams S, Fogliano M, Baldini G, Lodish HF. A novel serum protein similar to C1q, produced exclusively in adipocytes. J Biol Chem 1995; 270: 26746-26749.

18. Shimada K, Miyazaki T, Daida H. Adiponectin and atherosclerotic disease. Clin Chim Acta 2004; 344: 1-12
19. Sjodin AM, Forslund AH, Westerterp KR, Andersson AB, Forslund JM, Hambraeus LM. The influence of physical activity on BMR. Med Sci Sports Exerc 1996; 28: 85-91.

20. Statnick MA, Beavers LS, Conner LJ, Corominola H, Johnson D, Hammond CD et al. Decreased expression of apM1 in omental and subcutaneous adipose tissue of humans with type 2 diabetes. Int J Exp Diabetes Res 2000; 1: 81-88.

21. Trujillo ME, Scherer PE. Adiponectin - journey from an adipocyte secretory protein to biomarker of the metabolic syndrome. J Intern Med 2000; 257: 167-175.

22. Varady KA, Bhutani S, Church EC, Phillips SA. Adipokine responses to acute resistance exercise in trained and untrained men. Med Sci Sports Exerc 2010; 42 (3): 456-462.

23. Weinsier RL, Schutz Y, Bracco D. Re examination of the relationship of resting metabolic rate to fat-free mass and to the metabolically active components of fat-free mass in humans. Am J Clin Nutr 1992; 55: 790-794.

24. Whatley JE, Gillespie WJ, Honig J, Walsh MJ, Blackburn AL, Blackburn GL. Does the amount of endurance exercise in combination with weight training and a very-lowenergy. 2003

25. Kraemer WJ, Ratames NJ. Fundamentals of Resistance Training: Progression and Exercise Prescription. Medicne Sci Sports Exercise 2000; 0195-9131/04/3604-0674.

26. Yatagai T, Nishida Y, Nagasaka S. Relationship between exercise training-induced increase in insulin sensitivity and adiponectinemia in healthy men. Endocrine J 2003; 50: 233-238.

27. Zeng Q, Isobe K, Fu L, Ohkoshi N, Ohmori H, Takekoshi K, Kawakami Y. Effect of exercise on adiponectin and adiponectin receptor levels in rats. Life Sciences 2007; 80: 454-459.

Received March 6, 2011. Accepted August 18, 2012. 